\title{
Expression of mRNA TNF $\alpha$ and level of protein TNF $\alpha$ after exposure SCD40L in bone marrow mononuclear cells of myelodysplastic syndromes
}

\author{
Anggraini Iriani ${ }^{1}$, Rahayuningsih D. Setiabudy ${ }^{2}$, Siti B. Kresno ${ }^{2}$, Aru W. Sudoyo ${ }^{3}$, Saptawati Bardosono ${ }^{3}$, \\ Andhika Rachman ${ }^{3}$, Alida R. Harahap ${ }^{2}$, Mansyur Arief ${ }^{4}$ \\ ${ }^{1}$ Department of Clinical Pathology, Yarsi University, Jakarta, Indonesia; ${ }^{2}$ Department of Clinical Pathology, University of Indonesia, Jakarta, \\ Indonesia; ${ }^{3}$ Department of Hematology and Medical Oncology, University of Indonesia, Jakarta, Indonesia; ${ }^{4}$ Department of Clinical Pathology, \\ Hasanudin University, Makasar, Indonesia \\ Contributions: (I) Conception and design: All authors; (II) Administrative support: All authors; (III) Provision of study materials or patients: All \\ authors; (IV) Collection and assembly of data: All authors; (V) Data analysis and interpretation: All authors; (VI) Manuscript writing: All authors; (VII) \\ Final approval of manuscript: All authors. \\ Correspondence to: Anggraini Iriani, MD, PhD. Clinical Pathologist, Department of Clinical Pathology, Yarsi University, Jakarta, Jl. Letjen Suprapto, \\ Cempaka Putih, Jakarta 10510, Indonesia. Email: anggra_iriani@yahoo.com; anggraini.iriani@yarsi.ac.id.
}

Background: Cytopenia is the primary phenomenon in myelodysplastic syndrome (MDS) amidst hypercellular bone marrow. The soluble CD40 ligand (sCD40L) is considered as a cytokine that can trigger synthesis of tumor necrosis factor $\alpha(\mathrm{TNF} \alpha)$ that promotes apoptosis. The objective of this study is to prove that recombinant human sCD40L (rh-sCD40L) exposure on bone marrow mononuclear cells (BMMC) MDS increases TNF $\alpha$ expression at mRNA level and at protein level.

Methods: BMMC from MDS patients whom diagnosed and classified using the WHO 2008 criteria, were exposed to rh-sCD40L and antiCD40L. The expressions of TNF $\alpha$ mRNAs were quantified by qRT-PCR, level of TNF $\alpha$ were measured using the ELISA method.

Results: Exposure of rh-sCD40L significantly increased the expression of TNF $\alpha$ mRNA. The similar exposure also significantly increased the level of TNF $\alpha$ compared to controls. TNF $\alpha$ mRNA expression on BMMC in MDS samples exposed to rh-sCD40L is 3.32 times compared to TNF $\alpha$ mRNA expression without exposure. level of TNF $\alpha$ in supernatant media exposed to rh-sCD40L in MDS samples was higher than that of control samples which were 44.44 and $4.85 \mathrm{pg} / \mathrm{mL}, \mathrm{P}=0.018$.

Conclusions: The sCD40L plays a role in increasing the synthesis of $\mathrm{TNF} \alpha$ in $\mathrm{mRNA}$ level and protein level in BMMC MDS.

Keywords: Tumor necrosis factor $\alpha(\mathrm{TNF} \alpha)$; recombinant human soluble CD40 ligand (rh-sCD40L); antiCD40L; myelodysplastic syndrome (MDS); bone marrow mononuclear cell (BMMC)

Received: 31 May 2020; Accepted: 10 March 2021; Published: 29 March 2021.

doi: $10.21037 /$ sci-2020-025

View this article at: http://dx.doi.org/10.21037/sci-2020-025

\section{Introduction}

According to the $2008 \mathrm{WHO}$ classification, myelodysplastic syndrome (MDS) is one of five major categories of myeloid malignancy (1). In general population, the incidence of MDS is about 2-4/100,000/year, especially over 65 years of age. MDS can transform into acute myeloid leukemia in about $40 \%$ of cases. The increase in life expectancy causes an increase in the number of elderly population. Consequently, MDS cases are becoming more common, with cytopenia as the main symptom. This health issue also requires more attention as it possesses challenges to improve the quality of life of the elderly patients $(2,3)$. 
Table 1 Primary sequens $\beta$ actin and TNF $\alpha$

\begin{tabular}{lcl}
\hline Primer & Size (bp) & Sequens 5'-3' \\
\hline \multirow{3}{*}{$\beta$ actin (8) } & 21 & Forward: GGA TGC AGA AGG AGA TCA CTG \\
& 20 & Reverse: CGA TCC ACA CGG AGT ACT TG \\
& 21 & Forward: CCC AGG GAC CTC TCT CTA ATC \\
TNF $\alpha$ (8) & 21 & Reverse: ATG GGC TAC AGG CTC GTC ACT \\
\hline
\end{tabular}

The number of MDS patients annually will increase as well in the future (4). The responsibility to increase quality of life, primarily in geriatric population, makes MDS one of the health problems which needs to be addressed.

Cytopenia is the main phenomenon in MDS despite the hypercellular bone marrow. Some experts postulate suspect ineffective hematopoiesis caused by an increase in hematopoietic cells apoptosis, along with increased intra-medullar proliferation or self-renewal ability. The microenvironment of the bone marrow consists of an impeccable complex structure that facilitates progenitor cells to regulate proliferation, differentiation, and selfrenewal process by providing the necessary factors such as nutrition, growth factors, and cytokines. However, the bone marrow's microenvironment having MDS shows interaction between cells, as well as cells with cytokines, that influence the pathogenesis of MDS $(1,5)$.

Increased soluble CD40 ligand (sCD40L) cytokine is observed in MDS. And it is known that the interaction between sCD40L and CD40 increases cell endurance and proliferation, enhances the secretion of cytokines such as interleukin (IL), and tumor necrosis factor $\alpha(\mathrm{TNF} \alpha)(6)$, triggers apoptosis as well as the differentiation of CD34+ and stromal cells. The sCD40L is considered a cytokine that can trigger the synthesis of $\mathrm{TNF} \alpha$ as the proapoptotic cytokine in MDS. Hence, sCD40L may potentially be a biomarker to predict the worsening of MDS (7). This study aims evaluate the role of recombinant human $\mathrm{SCD} 40 \mathrm{~L}$ (rhsCD40L) exposure in inducing the synthesis of TNF $\alpha$ in hematopoietic progenitor cells.

We present the following article in accordance with the MDAR reporting checklist (available at http://dx.doi. org/10.21037/sci-2020-025).

\section{Methods}

The study was a cross sectional study. It is meant to observe the induction of proapoptotic cytokine TNF $\alpha$ on MDS derived hematopoiesis progenitor cells. The MDS diagnosis was determined, based on the results of clinical examination, complete hematology, peripheral blood morphology, bone marrow morphology, and cytogenetics, that met the 2008 WHO diagnostic criteria of MDS. Samples were subjects seeking treatment in the hematology clinic of Cipto Mangunkusumo Hospital (RSCM), Jakarta, Indonesia that give consent to enter the study. The study was conducted in accordance with the Declaration of Helsinki (as revised in 2013). The study was approved by the Ethics Committee of the Faculty of Medicine University of Indonesia (No. 673/ UN2.F1/ETIK/2015), and informed consent was taken from all individual participants.

Isolation of bone marrow mononuclear cells (BMMC) was performed based on the difference in density gradient centrifugation using Ficoll Paque medium (GE Healthcare $^{\mathrm{TM}}$, Sweden).

Exposure of $1.33 \mathrm{ng} / \mathrm{uL}$ rh-sCD40L (R\&D systems ${ }^{\mathrm{TM}}$, USA) was performed at the density of 300,000 BMMC, within $300 \mu \mathrm{L}$ StemMACS Hemopoetic Stem Cell media (StemMACS HSC Miltenyi Biotec ${ }^{\mathrm{TM}}$, USA) using a 24-well culture plate. Exposure time was determined at 18 hours and incubated at $37{ }^{\circ} \mathrm{C}$ with $5 \% \mathrm{CO}_{2}$. The principle of exposure is to expose rh-sCD40L on the BMMC, rhsCD40L is expected to induce the synthesis of TNF $\alpha$ and VEGF which can be examined at mRNA level inside the cells and in form of protein level in culture media.

Measurement of TNF $\alpha$ mRNA expressions was performed using commercial reagent kit (Qiagen ${ }^{\mathrm{TM}}$, Germany), in which RNA extraction process as well as cDNA synthesis and readings on qRT-PCR (Roche) machine. Target mRNA is the mRNA acquired from the cells exposed to CD40L and antiCD40L. Control mRNA is the mRNA acquired from the unexposed cells.

The mRNA expression was calculated using a relative calculation of $\beta$ actin housekeeping gene by measuring the threshold cycle. The value obtained was then normalized with the $\beta$ actin reference gene using the comparative quantification method. The primary sequens of target gene TNF $\alpha$ and housekeeping gene $\beta$ actin (8), used in the procedure shows in Table 1. Measurement of TNF $\alpha$ levels was performed by ELISA (Quantikine Elisa human R \& D system $^{\mathrm{TM}}$, USA).

Data obtained were then processed and analyzed using Statistical Package for the Social Sciences (SPSS) software. Analysis of differences between two unpaired groups was performed using t-test or Mann Whitney test. 
Table 2 Characteristics of the study subjects

\begin{tabular}{|c|c|c|c|c|c|c|}
\hline Case subjects & Sex & Age (year) & Cytopenia & Blas (\%) & Bone marrow morphology & IPSS-R* [score] \\
\hline 2 & M & 56 & Bicytopenia & 1.5 & RCUD & Intermediate [4.5] \\
\hline 3 & $\mathrm{~F}$ & 59 & Pancytopenia & 1.5 & RCUD & Very high [7] \\
\hline 4 & M & 60 & Bicytopenia & 1.5 & RCUD & NA \\
\hline 6 & $\mathrm{~F}$ & 76 & Bicytopenia & 3.5 & RCMD & Low [2.5] \\
\hline 7 & $\mathrm{~F}$ & 75 & Bicytopenia & 4.0 & RCMD & Intermediate [4.5] \\
\hline 8 & $\mathrm{~F}$ & 55 & Pancytopenia & 1.0 & RCMD & Very low [1] \\
\hline 9 & $\mathrm{~F}$ & 17 & Pancytopenia & 1.0 & RCMD & NA \\
\hline 12 & M & 78 & Pancytopenia & 5.0 & RAEB-1 & Very high [7.5] \\
\hline 13 & $\mathrm{~F}$ & 62 & Bicytopenia & 7.0 & RAEB-1 & Intermediate [4] \\
\hline 14 & $\mathrm{~F}$ & 27 & Pancytopenia & 5.5 & RAEB-1 & Intermediate [4.5] \\
\hline 15 & $M$ & 70 & Pancytopenia & 6.5 & RAEB-1 & High [6] \\
\hline
\end{tabular}

M, male; F, female; RCUD, refractory cytopenias with unilineage dysplasia; RCMD, refractory anemia with multilineage dysplasia; RAEB-1, refractory anemia with excess blast-1; NA, not applicable. *, IPSS-R, International Prognostic Scoring System-Revised.

Table 3 Relative expression of TNF $\alpha$ mRNA without exposure, exposed to rh-sCD40L and exposed to antiCD40L in MDS derived-BMMC

\begin{tabular}{lcccc}
\hline Without exposure & Exposure to rh-sCD40L & Exposure to antiCD40L & $P$ value & $P$ value \\
\hline 1.00 & $3.32(1.10)$ & $2.83(0.94)$ & 0.047 & 0.031 \\
\hline
\end{tabular}

Data presented in mean (standard deviation). ${ }^{*}$, paired $t$-test (between without exposure and exposed to rh-sCD40L). ${ }^{\star *}$, paired $t$-test (between exposed to rh-sCD40L and exposed to antiCD40L). Significant difference if $\mathrm{P}<0.05$. BMMC, bone marrow mononuclear cell; MDS, myelodysplastic syndrome; TNF $\alpha$, tumor necrosis factor $\alpha$.

\section{Results}

Table 2 shows characteristics of the study subjects, 15 samples of bone marrow aspirates were taken from MDS patients, comprised 7 male patients and 8 female patients. There were 8 samples of bone marrow aspirates from lymphoma patients as control subjects. The age range of case subjects in this study is $17-78$ years old. The number of case subjects with age $\geq 60$ years old were 9 people, and those with age $<60$ years old were 6 people, 2 of them were young patients aged 17 and 27 years old. Mean of MDS patients' age in this study is 58.9 years old. Almost all case subjects underwent cytopenia in more than 1 lineage. Diagnoses of bone marrow morphology in case subjects were 4 refractory cytopenias with unilineage dysplasia
(RCUD), 7 refractory anemia with multilineage dysplasia (RCMD), and 4 refractory anemia with excess blast-1 (RAEB-1). Diagnosis of MDS was established based on 2008 WHO criteria, which are peripheral blood and bone marrow morphology examinations. In order to establish the diagnosis, it is extremely necessary to get specific finding in bone marrow smear, which is dysplasia in minimum $10 \%$ of the involved cell lineage.

Mean level of relative TNF $\alpha$ mRNA expression on BMMC in MDS samples exposed to rh-sCD40L and exposed to antiCD40L are 3.32 and 2.83 times compared to TNF $\alpha$ mRNA expression without exposure with expression of 1.00, shows in Table 3 and Figure 1.

Level of TNF $\alpha$ protein in supernantant media in the MDS group exposed to rh-sCD40L was significantly higher 


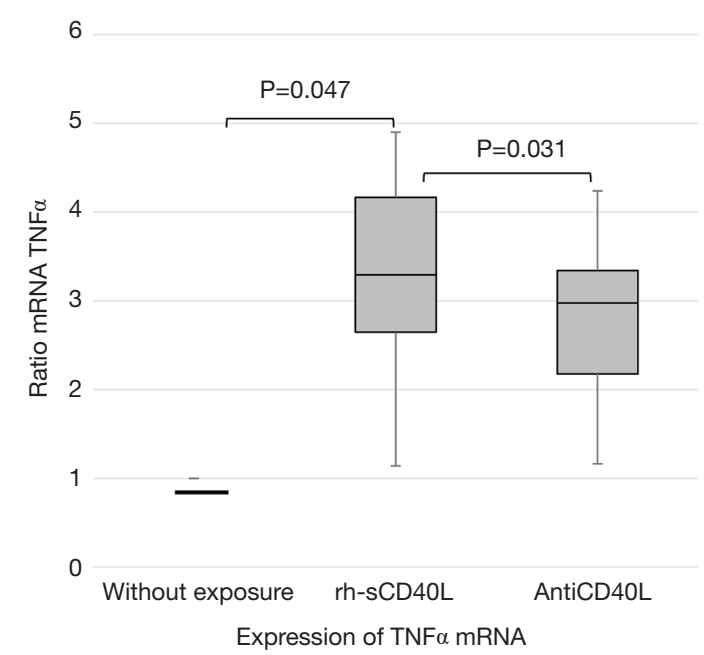

Figure 1 Relative expression of TNF $\alpha$ mRNA. Paired $t$-test used to analyze TNF $\alpha$ mRNA expression on BMMC in MDS samples exposed to rh-sCD40L and exposed to antiCD40L, showed significant difference with $\mathrm{P}=0.047$, similar to samples exposed to antiCD40L and exposed to rh-sCD40L which showed significant difference with $\mathrm{P}=0.031$. MDS, myelodysplastic syndrome; $\mathrm{BMMC}$, bone marrow mononuclear cell; $\mathrm{TNF} \alpha$, tumor necrosis factor $\alpha$.

than without exposure $(\mathrm{P}<0.05)$, with mean respectively were 44.46 and $14.12 \mathrm{pg} / \mathrm{mL}$.

The level of TNF $\alpha$ protein in supernatant media between MDS samples and control samples without exposure showed no significant difference.

The level of TNFa in supernatant media exposed to rh-sCD40L in MDS samples was higher than control samples, the mean respectively were 44.44 and $4.85 \mathrm{pg} / \mathrm{mL}$ $(\mathrm{P}=0.018)$.

The level of TNF $\alpha$ in supernatant media exposed to antiCD40L between MDS samples and control samples also showed significant difference with $\mathrm{P}=0.038$, shows in Table 4 .

\section{Discussion}

\section{Characteristics of subjects}

A total of 15 cases of MDS and 8 controls was included. In this study, the mean age of MDS patients was 58.9 years. Other Asian studies reported that MDS occurred on a younger age, i.e., 53 years on average (9). Based on the bone marrow morphology, there were 4 RCUD, 7 RCMD, and 4 RAEB-1.

In this study, most of the cytogenetic examination results
Table 4 Level of TNF $\alpha$ protein without exposure, exposed to rh-sCD40L and exposed to antiCD40L, in supernatant media $(\mathrm{pg} / \mathrm{mL})$

\begin{tabular}{lccc}
\hline Exposure & MDS & Control & P value* $^{*}$ \\
\hline Without exposure & $14.12(3.71)$ & $9.97(2.19)$ & 0.421 \\
rh-sCD4OL & $44.46(5.65)$ & $4.85(1.70)$ & 0.018 \\
AntiCD40L & $36.90(4.61)$ & $8.87(2.25)$ & 0.038 \\
\hline
\end{tabular}

Data presented in mean (standard deviation). *, independent $t$-test. Significant difference if $\mathrm{P}<0.05$. MDS, myelodysplastic syndrome; TNF $\alpha$, tumor necrosis factor $\alpha$.

were abnormal, some would even show multiple karyotype disorders. According to the previous study, $40 \%$ of MDS patients have normal karyotypes, and about $10-18 \%$ have multiple karyotype disorders. It is known that abnormal karyotype is associated with poor prognosis $(10,11)$. In this study, it seemed that most of the MDS case subjects coming to the hematology clinic were already in an advanced stage, which were consistent with the high IPSS score. These patients had been suffered from refractory cytopenia, more than one cytopenia, or multiple cytogenetic abnormalities.

On these subjects, prognostic risk was calculated based on the revised International Prognostic Scoring System (IPSS-R), the number of blast count, Hb level, platelet and neutrophil count, as well as cytogenetic results (12). Therefore, the prognostic risk was established conventionally based on the bone marrow morphology diagnoses, i.e., 4 high-risk subjects (RAEB-1) and 11 lowrisk subjects (RCUD, RCMD).

\section{Exposure of rb-sCD40L to BMMC MDS towards increased TNFa expression at the $m R N A$ level}

mRNA examinations in this study were conducted by qRTPCR quantification. This method is most commonly used as it has high sensitivity, specificity, and reproducibility. Quantification of mRNA with qRT-PCR can be in the form of relative and absolute quantification. This study checked relative quantification using the housekeeping gene, which was $\beta$ actin. Housekeeping gene refers to a normal gene expressed in all cells, and hence the number does not vary and can be used to normalize the gene being studied.

The process of RNA extraction showed RNA concentration of $1.1-58 \mathrm{ng} / \mu \mathrm{L}$ with ratio or purity was $>2$. cDNA synthesis using qRT PCR showed cDNA level of $482-3,764 \mathrm{ng} / \mu \mathrm{L}$. Positive and negative control for 
TNF $\alpha$ mRNA, and $\beta$ actin showed good results. mRNA expression without exposure is normalized with expression of 1.00. Relative TNF $\alpha$ mRNA expression on BMMC without exposure, with rh-sCD40L exposure, and addition of antiCD40L before being exposed to rh-sCD40L are identified.

TNF $\alpha$ expressions can be measured at mRNA level and protein level. The mRNA level can be measured in cell cytoplasm, while protein TNF $\alpha$ is expected to be in culture media, since it is the secreted protein. Therefore, measurement of TNF $\alpha$ level in culture media was performed using ELISA method. Supernatant media from BMMC culture with treatment without exposure, exposed to $\mathrm{CD} 40 \mathrm{~L}$, and exposed to antiCD40L prior to exposure of rh-sCD40L, was examined for TNFa level using ELISA method.

The BMMC groups without exposure are normalized by considering the differences in expression between the target gene and the $\beta$-actin housekeeping gene, thus the relative $\mathrm{TNF} \alpha \mathrm{mRNA}$ expression without exposure is considered as one (1). In the BMMC MDS group exposed to rh-sCD40L there was a significantly increased TNF $\alpha$ mRNA expression compared to those without exposure. Similarly, the TNF $\alpha$ mRNA expression in BMMC MDS exposed to antiCD40L was significantly lower compared to the TNF $\alpha$ mRNA expression exposed to rh-sCD40L. This means that there is an in vitro interaction between rh-sCD40L and its receptor in the surface of BMMC MDS which will then activate the intracellular signals for the synthesis of TNF $\alpha$, even though the interactions between receptors and ligands were not proven in this study.

MDS-derived BMMC that exposed to rh-sCD40L shows a significant increase of TNF $\alpha$ mRNA expression $(\mathrm{P}<0.05)$ compared to MDS-derived BMMC that was not exposed to rh-sCD40L and exposed to anti CD40L. The protein level of TNF $\alpha$ of MDS-derived BMMC conditioned medium after rh-sCD40L exposure were also significantly higher compared to control group.

Mean level of relative TNF $\alpha$ mRNA expression on BMMC in MDS samples exposed to rh-sCD40L and exposed to antiCD40L is 3.32 and 2.83 times compared to TNF $\alpha$ mRNA expression without exposure with expression of 1.00 .

This result show that in MDS derived BMMC group, rh-sCD40L interacts with CD40 and then activates intracellular signal to significantly trigger the expression of $\mathrm{TNF} \alpha \mathrm{mRNA}$. However, these findings did not contradict other studies where TNF $\alpha$ level in MDS bone marrow has been found higher than normal. Another study reported that mean production of TNF $\alpha$ was found higher than normal upon rh-sCD40L exposure, i.e., at 125 and $120 \mathrm{pg} / \mathrm{mL}$, and that administration of antiCD40L antibody has been shown to decrease TNF $\alpha$ synthesis, compared to nonadministration (13-16).

The TNF $\alpha$ mRNA expression in the administration of antiCD40L in the MDS group was lower compared to the administration of rh-sCD40L, even though it did not reach a value approaching the baseline, it was proven that the antiCD40L effects can reduce the TNF $\alpha$ mRNA significantly. In this study, the exposure volume of antiCD40L given was the same as the exposure volume of rh-sCD40L. Because the molecules of antiCD40L antibody $(150 \mathrm{kDa})(17)$, is larger than the rh-sCD40L molecule $(16.9 \mathrm{kDa})(18)$, there seems to be an imperfect inhibitory effect by the antiCD40L antibody molecule towards sCD40L in the trial wells. There is still a possibility of CD40L membranes or rh-sCD40L are not inhibited properly by antiCD40L. The provision of antiCD40L in this invitro trial was expected to inhibit the active sites of CD40L, both in the membrane-bound form and in a dissolved form (sCD40L). This treatment would cause no interaction between rh-sCD40L with its receptors when rh-sCD40L was added, and therefore would decrease the TNF $\alpha$ mRNA expression significantly. This finding answers the hypothesis that CD40L can increase the TNF $\alpha$ mRNA expression and this effect can be decreased by the provision of antiCD40L.

It has been proven that CD40L, also referred to as CD154, is the only ligand for CD40, and therefore the possibility of another ligand binding to CD40 is negligible. Other publications also suggested that even though CD40 is a classic receptor for CD $40 \mathrm{~L}$, molecules such as $\alpha 5 \beta 1$, $\alpha M \beta 2$, and $\alpha \operatorname{IIb} \beta 3$ were found to be new receptors for CD40L. These receptors have biological effect particularly in triggering the activation of thrombocytes. It has not yet been proven whether $\mathrm{sCD} 40 \mathrm{~L}$ interacts with these receptors in every cell or cross links between these receptors which are expressed on the same cell (19).

Previous studies have reported that CD40 ligation leads to cellular proliferation, increasing self-renewal abilities, and producing a number of cytokines. CD40CD40L interactions have proven to contribute to the immune mediation process and provides a potential role, where currently CD40L is rationally designed to facilitate the desired target effects. The effects of CD40L in the pathogenesis of several blood malignancy diseases and 
cardiovascular diseases have been known and used for targeted therapy using CD40L antibodies in the commercial form as antiCD40L or CD154 recombinant. Meers et al. (20) found a high expression of CD40 in MDS monocytes, and a high expression of CD40L in the surface of active $T$ helper lymphocytes, both in the MDS peripheral blood as well as bone marrow. There is a correlation between increased CD40 expression and bone marrow failure in MDS. Considering the many surface molecules in the surface of monocytes that play a role in inflammatory reactions, an increase in the number of monocytes is also linked to worsening of MDS, the reason being that monocyte is one of the TNF $\alpha$ producing cells $(21,22)$. Increased monocytes are seen in CMML that has previously been classified as part of MDS/MPN, but separated from MDS in the WHO classification $(23,24)$.

\section{Exposure of rh-sCD40L to BMMC MDS towards increased TNFa level at protein level}

$\mathrm{TNF} \alpha$ produced at the mRNA level is then translated into $\mathrm{TNF} \alpha$ protein. This process is continuously proven by checking the TNFa levels in the supernatant media using the ELISA method. Messenger RNA is a subtype of RNA that carries part of the DNA code to the ribosome to be processed. mRNA is formed in the transcription process in the form of a nucleotide chain. mRNA carries information on the amino acid structure to the ribosome to be used as a protein template. mRNA examination is a good indicator to evaluate gene regulations. In the invitro process, the amount of mRNA illustrates the expression of native proteins secreted, and at the post-transcription phase, the mRNA will be immediately translated at the final phase of protein synthesis. This result answered the continuation of TNF $\alpha$ synthesis process. The TNF $\alpha$ mRNA at the transcription stage was continued to the translation stage and synthesized into proteins then secreted.

There have been many reports of increasing TNFa level in MDS bone marrow, the problem is that the source of TNF $\alpha$ increase needs to be identified. A number of studies have tried to answer this phenomenon. TNFa in the bone marrow is mainly produced as cytokine or paracrine by progenitor cells, mesenchymal cells, or as endocrine from sources elsewhere. TNF $\alpha$ can also be synthesized secondary to activation of other cytokines $(6,14,16,25)$. An invitro experiment by exposing PBMC cancer patients with sCD40L and then examined the level of cytokines in their supernatant media; they found increased levels of TNF $\alpha$ and TGF $\beta$, IL10, and GMCSF (26).

TNF $\alpha$ level in the supernatant media that was significantly higher than TNF $\alpha$ mRNA expression in this study can occur for several reasons. Sometimes there is a discrepancy between the expression of mRNA and the level of protein produced; this condition can be caused by biological and technical factors. There are six biological factors that influence the relationship between mRNA expression and protein complexes (27).

(I) The transcription process is not efficient because there is no perfect complementary regulatory RNA, so not all RNAs are translated into proteins in a balanced manner. (II) The role of regulator proteins in RNA assembly in ribosomes that regulate affinity, and stability of RNA (sRNA) for translational efficiency. (III) Codon bias and codon adaptation index, the codon will become a template for the anticodon. High codon bias will affect the genes expressed. (IV) Density of ribosomes and ribosome capacity. Translation efficiency is the number of complete protein molecules produced per mRNA at a time. The density of ribosomes, namely the number of ribosomes per transcriptional unit or the availability of ribosomes, determines this efficiency. Translation efficiency occurs when the amount of protein synthesis increases with a small amount of mRNA. The protein content produced correlates better with the number of ribosomes where mRNA is attached, compared to just looking at the amount of mRNA. (V) The post-translation factor that affects the result of protein synthesis is the half-life of protein. Protein half-life can range from seconds to several days characterized by protein stability, phosphorylation process and protein location. (VI) Biological factor, which is ribosome availability that causes a lot of efficient translation. But sometimes there are mRNAs that are not translated. In eukaryotic cells the distribution and spread of mRNA in the cell compartment also affect translational velocity (27). In this study, the six factors can affect variations of TNFa synthesis at mRNA and protein level.

The findings of this study can answer the hypothesis of exposure of CD40L to increase TNF $\alpha$ synthesis at protein level. From the findings of TNF $\alpha$ synthesis at both mRNA level and protein level, it can answer the pathogenesis that biomarker of SCD40L plays a role in inducing TNF $\alpha$ synthesis in BMNC MDS. Considering that the role of $\mathrm{TNF} \alpha$ as proapoptotic cytokine does not need to be contested again, thus the interaction of CD40-CD40L can predict an increase in apoptotic activity in the microenvironment of MDS patient's bone 




Figure 2 Scheme mechanism induction of TNFa synthesis by sCD40L on BMMC MDS. Scheme of this research model can explain that sCD40L interact with its receptors CD40, then activate TRAF molecules. TRAF will activate NF- $\kappa \mathrm{B}$ signal to activate DNA TNF $\alpha$ transcription process on nucleus. A copy gene in the DNA is created. Messenger RNA or mRNA function as blue print for protein. The mRNA then exits from nucleus and move to ribosom and create codon template. Translation process begin because transport RNA or tRNA supplies different anticodons matching the various codons of mRNA. After completion, a peptide bond is then formed consist of amino acid chain. This amino acid is folded to TNF $\alpha$ protein. TNF $\alpha$ is then formed out from MDS derived BMMC to become a cytokine which serve as its function. MDS, myelodysplastic syndrome; BMMC, bone marrow mononuclear cell; TNF $\alpha$, tumor necrosis factor $\alpha$.

marrow, shows in Figure 2.

\section{Conclusions}

The exposure of $\mathrm{sCD} 40 \mathrm{~L}$ in MDS BMMC has been shown to increase the TNF $\alpha$ expression, and the exposure of antiCD40L has been shown to reduce the TNF $\alpha$ expression at the mRNA level.

The exposure of sCD40L in MDS BMMC has been shown to increase the TNF $\alpha$ expression, and the exposure of antiCD40L has not been shown to reduce the TNF $\alpha$ level at the protein level.

This study has shown that $\mathrm{SCD} 40 \mathrm{~L}$ has a role in inducing the synthesis of the proapoptotic cytokine TNF $\alpha$ within the bone marrow mononuclear cells of MDS patients.

\section{Acknowledgments}

Funding: None.

\section{Footnote}

Reporting Checklist: The authors have completed the MDAR reporting checklist. Available at http://dx.doi.org/10.21037/ sci-2020-025

Conflicts of Interest: All authors have completed the ICMJE uniform disclosure form (available at http://dx.doi. org/10.21037/sci-2020-025). Dr. AI reports in addition, she has a patent (Title: "Skema Mekanisme Induksi Sintesis TNFa Oleh SCD40L Pada BMMC MDS"; Entity: Universitas Indonesia) licensed to EC00201931070, 26 
February 2019. The other authors have no conflicts of interest to declare.

Ethical Statement: The authors are accountable for all aspects of the work in ensuring that questions related to the accuracy or integrity of any part of the work are appropriately investigated and resolved. The study was conducted in accordance with the Declaration of Helsinki (as revised in 2013). The study was approved by the Ethics Committee of the Faculty of Medicine University of Indonesia (No. 673/UN2.F1/ETIK/2015), and informed consent was taken from all individual participants.

Open Access Statement: This is an Open Access article distributed in accordance with the Creative Commons Attribution-NonCommercial-NoDerivs 4.0 International License (CC BY-NC-ND 4.0), which permits the noncommercial replication and distribution of the article with the strict proviso that no changes or edits are made and the original work is properly cited (including links to both the formal publication through the relevant DOI and the license). See: https://creativecommons.org/licenses/by-nc-nd/4.0/.

\section{References}

1. Tefferi A, Vardiman JW. Mechanisms of disease myelodysplastic syndromes. N Engl J Med 2009;361:1872-85.

2. Valent P, Horny HP, Bennett JM, et al. Definitions and standards in the diagnosis and treatment of the myelodysplastic syndromes: Consensus statements and report from a working conference. Leuk Res 2007;31:727-36.

3. Vardiman JW, Thiele J, Arber DA, et al. The 2008 revision of the World Health Organization (WHO) classification of myeloid neoplasms and acute leukemia: Rationale and important changes. Blood 2009;114:937-51.

4. Statistics Indonesia Body, United nation Population Fund. Indonesia population project. 2015-2045. 2101015. 2018.

5. Aleshin A, Greenberg PL. Molecular pathophysiology of the myelodysplastic syndromes insight for targeted therapy. Blood Adv 2018;2:2787-97.

6. Tian T, Wang M, Ma D. TNF $\alpha$ a good or bad factor in hematological diseases? Stem Cell Investig 2014;1:12.

7. Mavroudi I, Papadaki V, Velegraki M, et al. Distribution and function of cd40/cd40l in the bone marrow granulocytic progenitor and precursor cells, possible pathophysiologic significance. Haematologica
2008;93:236.

8. Stordeur P, Poulin LF, Craciun L, et al. Cytokine mRNA quantification by real time PCR. J Immunol Methods 2002;259:55-64.

9. Corey SJ, Minden MD, Barber DL, et al. Myelodysplastic syndromes the complexity of stem cell diseases. Nat Rev Cancer 2007;7:118-29.

10. Alcedo P, Andrade E, Hamad H, et al. Cytogenetic, inflammatory, immunologic, and infections basis for dysplastic hematopoiesis. Oncol Hematol Rev 2017;13:81-91.

11. Haase D. Cytogenetic features in myelodysplastic syndromes. Ann Hematol 2008;87:515-26.

12. Greenberg PL, Tuechler H, Schanz J, et al. Revised international prognostic scoring system for myelodysplastic syndromes. Blood 2012;120:2454-65.

13. Kim HO, Kim HS, Youn JC, et al. Serum cytokine profiles in healthy young and elderly population assessed using multiplexed bead-based immunoassays. J Transl Med 2011;9:113.

14. Kittang AO, Sand K, Brenner AK, et al. The systemic profile of soluble immune mediators in patients with myelodysplastic syndromes. Int J Mol Sci 2016;17:1080.

15. Hock BD, McKenzie JL, Patton NW, et al. Circulating levels and clinical significance of soluble cd 40 in patients with hematologic malignancies. Cancer. 2006;106:2148-57.

16. Kerbauy DB, Deeg HJ. Apoptosis and anti-apoptotic mechanisms in the progression of MDS. Exp Hematol 2007;35:1739-46.

17. R\&D systems. Human CD40L/TNFsf5 antibody monoclonal mouse igg2b. R\&D Systems Biotechne.1-2.

18. R\&D systems. Recombinant human cd401/tnfsf5 aa 108261. R\&D System Biotechne.1-2.

19. Michel NA, Zirlik A, Wolf D. CD40L and Its Receptors in Atherothrombosis-An Update. Front Cardiovasc Med 2017;4:40.

20. Meers S, Kasran A, Boon L, Lemmens J, et al. Monocytes are activated in patients with myelodysplastic syndromes and can contribute to bone marrow failure through CD40-CD40L interactions with T helper cells. Leukemia 2007;21:2411-9.

21. de Jong PR, Schadenberg AWL, van den Broek T, et al. STAT3 regulates monocyte TNF-alpha production in systemic inflammation caused by cardiac surgery with cardiopulmonary bypass. PLoS One 2012;7:e35070.

22. Pollyea DA, Hedin BR, O'Connor BP, et al. Monocyte function in patients with myelodysplastic syndrome. $\mathrm{J}$ Leukoc Biol 2018;104:641-7. 
23. Arber DA, Orazi A, Hasserjian R, et al. The 2016 revision to the World Health Organization classification of myeloid neoplasms and acute leukemia. Blood 2016;127:2391-405.

24. Solary E, Itzykson R. How i treat chronic myelomonocytic leukemia. Blood 2017;130:126-36.

25. Raza A, Gezer S, Mundle S, et al. Apoptosis in bone marrow biopsy samples involving stromal and

doi: $10.21037 /$ sci-2020-025

Cite this article as: Iriani A, Setiabudy RD, Kresno SB, Sudoyo AW, Bardosono S, Rachman A, Harahap AR, Arief M. Expression of mRNA TNF $\alpha$ and level of protein TNF $\alpha$ after exposure sCD40L in bone marrow mononuclear cells of myelodysplastic syndromes. Stem Cell Investig 2021;8:6. hematopoietic cells in 50 patients with myelodysplastic syndromes. Blood. 1995;86:268-76.

26. Huang J, Jochems C, Talaie T, et al. Elevated serum soluble cd40 ligand in cancer patients may play an immunosuppressive role. Blood. 2012;120:3030-8.

27. Maier T. Correlation of mRNA and protein in complex biological samples. FEBS Lett 2009;583:3966-73. 